\title{
Early homeostatic disturbances of human growth and maturation by endocrine disrupters
}

\author{
Jean-Pierre Bourguignon and Anne-Simone Parent \\ Developmental Neuroendocrinology Unit, GIGA Neurosciences, University of Liège and Department of Pediatrics, CHU de Liège, Belgium
}

\section{Purpose of review}

We attempt to delineate and integrate aspects of growth and development that could be affected by endocrine disrupters [endocrine-disrupting compounds (EDC)], an increasing public health concern.

\section{Recent findings}

Epidemiological and experimental data substantiate that fetal and early postnatal life are critical periods of exposure to endocrine disrupters, with possible transgenerational effects. The EDC effects include several disorders of the reproductive system throughout life (abnormalities of sexual differentiation, infertility or subfertility and some neoplasia) and disorders of energy balance (obesity and metabolic syndrome). The mechanisms are consistent with the concept of 'developmental origin of adult disease'. They could involve crosstalk between the factors controlling reproduction and those controlling energy balance, both in the hypothalamus and peripherally.

\section{Summary}

Due to ubiquity of endocrine disrupters and lifelong stakes of early exposure, individual families should be provided by pediatricians with recommendations following the precautionary principle, that is prevention or attenuation of conditions possibly detrimental to health before the evidence of such adverse effects is complete and undisputable.

Keywords : adipogenesis ; development ; energy balance ; nutrition ; puberty ; reproduction

\section{Introduction}

Four decades ago, pioneering observations of endocrine disruption reported vaginal adenocarcinoma in adult daughters of women treated with diethylstilbestrol (DES) during pregnancy [1]. Since then, evidence has accumulated that numerous endocrine-disrupting compounds (EDCs) could cause disorders not only of the adult reproductive system but also of other aspects of homeostasis at different periods of life $\left[2^{\bullet}\right]$. Here, our aim is to review some general issues about EDCs, to focus on possible EDC effects on growth and development and to provide the pediatrician with some recommendations in order to minimize EDC exposure at critical periods of life.

\section{Definition of endocrine disrupters and affected aspects of growth and development}

An EDC was defined by the US Environmental Protection Agency (EPA) as 'an exogenous agent that interferes with synthesis, secretion, transport, metabolism, binding, action, or elimination of natural blood-borne hormones that are present in the body and are responsible for homeostasis, reproduction, and developmental process'.

Examples of EDCs are given in Table 1. As has been shown in the recent Third National Report by the Center for Disease Control [3], humans are exposed to hundreds of environmental chemicals, of which dozens are known as EDCs.

Some aspects of development that can be disrupted by EDCs are listed in Table 2 together with the phenotypic disturbances resulting from those effects, the endocrine systems affected and some examples of EDCs possibly 
involved. Direct brain effects on cortex and hippocampus can occur through disruption of thyroid hormone action [e.g. polychlorinated biphenyls (PCBs), bisphenol A (BPA)] with consequences on cognitive abilities. The brain is also involved in some central nervous system (CNS) aspects of sexual differentiation and the hypothalamic control of reproduction and energy balance. In the present review, we will focus on developmental aspects leading to the control of reproduction and energy balance and we will put emphasis on the interactions between both systems. We will not discuss the psychomotor development issues, which are obviously crucial but involve different pathogenetic mechanisms with thyroid hormones as key mediators.

Table 1 Examples of endocrine disrupting compounds in relation to origin and function

\begin{tabular}{lll}
\hline Origin & Function & Compounds \\
\hline Industrial & Incineration, insulation & Dioxins, polychlorinated biphenyls (PCBs) \\
& Surfactants, cleaning agents & Alkylphenols \\
Agricultural & Organochlorine pesticides, insecticides & $\begin{array}{l}\text { Dichlorodiphenyltrichloroethane (DDT), methoxychlor, } \\
\text { dieldrin, lindane, chlordecone }\end{array}$ \\
& & Atrazine, vinclozolin \\
& Herbicides, fungicides & Genistein, coumestrol \\
Domestic & Phytoestrogens (natural) & Phthalates \\
& Plasticizers & Bisphenol A (BPA) \\
& Resins, plastics & Polybrominated biphenyls (PBBs) \\
& Fire retardants & Parabens \\
& Cosmetics & Synthetic estrogens, diethylstilbestrol (DES) \\
\hline
\end{tabular}

Table 2 Sites and aspects of development possibly adversely affected by endocrine-disrupting compounds (EDCs), phenotypic expression, and disrupted hormonal systems

\begin{tabular}{|c|c|c|c|}
\hline $\begin{array}{l}\text { Sites and aspects of } \\
\text { development }\end{array}$ & Phenotypic expression & $\begin{array}{c}\text { Endocrine systems } \\
\text { primarily affected }\end{array}$ & $\begin{array}{l}\text { Examples of EDC } \\
\text { possibly involved }\end{array}$ \\
\hline Brain & $\begin{array}{l}\text { Impairment of cognitive and } \\
\text { psychomotor abilities }\end{array}$ & Thyroid hormones & PCBs, BPA \\
\hline Sexual differentiation & $\begin{array}{l}\text { Hypospadias, cryptorchidism, reduced } \\
\text { anogenital distance }\end{array}$ & Sex steroids & DES, phthalates \\
\hline \multicolumn{4}{|l|}{ Reproductive development } \\
\hline Female reproductive tract & Structural anomalies, cancer & Sex steroids & DES \\
\hline Breast & $\begin{array}{l}\text { Structural anomalies, premature } \\
\text { thelarche, cancer }\end{array}$ & & DES, DDT, BPA \\
\hline Testis & Oligospermia, germ cell cancer & & Phthalates, PCBs \\
\hline Prostate & Cancer & & DES, BPA, PCBs \\
\hline Neuroendocrine & $\begin{array}{l}\text { Pubertal timing variations, ovulatory } \\
\text { disorders, sexual behavior }\end{array}$ & & DDT, DES, PCBs \\
\hline $\begin{array}{l}\text { Adipose tissue and energy } \\
\text { balance }\end{array}$ & Visceral obesity, metabolic syndrome & $\begin{array}{l}\text { Peroxisome proliferator-activated } \\
\text { receptor (PPAR)- } \gamma \text {; sex steroids }\end{array}$ & BPA \\
\hline
\end{tabular}

\section{Limits in unravelling endocrine disrupter effects}

It is challenging to link exposure to particular EDCs and health issues for several reasons $\left[2^{\bullet}\right]$ summarized in Table 3. Humans as well as animals are likely exposed to a variety of EDCs acting as mixtures with time-related changes in compounds and doses. Mixtures result in more than additive effects, since compounds mixed at concentrations that were inactive when used as single EDCs have been shown to become active when used as mixtures [4]. The study of mixtures, however, is complex and laborious. So far the vast majority of studies have been performed with single classes of EDCs only. When exposure is assessed at the time of pubertal or adult disorders, there has been a very long period since fetal/ perinatal life, the most critical time for EDC effects. Sexual dimorphism is indeed a critical issue when EDC effects are considered. As a whole, EDCs appear to work either as estrogen agonists or as androgen antagonists with the ratio estrogen/androgen actions as an 
ultimate determinant of EDC effects [5]. Consistent with this concept is the observation that premature breast development can occur after exposure to phthalates, which are considered to act primarily as androgen antagonists [6]. Moreover, an estrogenic compound such as DDT can generate the antiandrogenic sub-product dichlorodiphenylchloroethene (DDE), which can also indirectly reflect previous exposure to DDT, further complicating the elucidation of estrogenic versus antiandrogenic effects [7]. Since both the reproductive and energy balance systems are regulated by feedback loops between peripheral tissues on the one hand and pituitary gland, hypothalamus and CNS on the other hand, EDCs can have an effect at any of those sites directly or secondarily through changes in hypothalamic-pituitary messengers or altered peripheral feedback. At a given cellular level, the mechanisms are complex, exerting both genomic and nongenomic effects on various types of receptors. These effects can be related to dose in a nonlinear manner (e.g. biphasic, U-shaped) as well [ $\left.2^{\circ}\right]$.

\section{Critical developmental windows of endocrine disruption}

As already pointed out, the DES story provided evidence that prenatal life was critical for occurrence of cancer in the offspring exposed to that EDC two to three decades earlier [1]. The critical role of fetal life for adult health has further emerged following Barker's observations of an inverse relationship between birth weight and the risk of death from cardiovascular diseases [8], leading to the concept of 'fetal basis of adult disease'. More recently, fetal and early postnatal periods appeared to be determinant for the effects of sex steroids [ $\left.9^{\bullet \bullet}\right]$ as well as nutrition [10] on the homeostasis of reproduction and energy balance throughout subsequent life. Thus, the concept was extended as 'developmental origin of adult health and disease'. Convincing data on the programming effects of sex steroids arose from prenatal exposure of the ovine fetus to testosterone, which caused alteration of pubertal timing and estrus cyclicity through neuroendocrine alteration of estradiol positive feedback [11]. In similar conditions, fetal lamb exposure to the EDCs methoxychlor or BPA accounted for delayed or severely reduced luteinizing hormone $(\mathrm{LH})$ surge, respectively, without change in pubertal timing [12]. The exposed animals also had ovarian anomalies, growth retardation and metabolic disorders that could contribute to disrupted reproductive function. Such an association of disorders could be related to the polycystic ovary syndrome (PCOS). This human condition was found to be integrated within a spectrum of anomalies (premature pubarche and metabolic syndrome) that are predicted by intrauterine growth retardation (IUGR) [13]. Another human condition consistent with early developmental EDC effects is the 'testicular dysgenesis syndrome' or TDS, an association of hypospadias, cryptorchidism, oligospermia and germ cell cancer that was proposed to result from disruption of embryonic/fetal programming and gonadal development [14]. In support of that hypothesis, Fisher et al. [15] reported a TDS-like condition after fetal rat exposure to phthalates.

Table 3 Relevant issues accounting for limits in identification of endocrine disrupting compound (EDC) involvement in health disorders

\begin{tabular}{|c|c|}
\hline Issues & Implication \\
\hline Low-dose mixtures & $\begin{array}{l}\text { Ineffective low doses of single EDCs become effective when associated with other EDCs. } \\
\text { Mixture effects (more likely reflecting human exposure in the real world than single } \\
\text { EDCs) are not simply additive, but studies are complex }\end{array}$ \\
\hline Latency & $\begin{array}{l}\text { At the time of adult expression of disorders determined by fetal or postnatal exposure to } \\
\text { EDCs, the demonstration of exposure is no longer possible }\end{array}$ \\
\hline $\begin{array}{l}\text { Agonist/antagonist of one or } \\
\text { several hormones }\end{array}$ & $\begin{array}{l}\text { A single EDC can be agonist at some subtypes of receptors to a steroid and antagonist at } \\
\text { others. It can interact with several hormonal systems that can each play different roles } \\
\text { depending on sex and stage of development }\end{array}$ \\
\hline $\begin{array}{l}\text { Nonconventional dose-response } \\
\text { relationship }\end{array}$ & $\begin{array}{l}\text { Some EDCs exhibit U-shaped or inverted-U curves of dose-response, meaning that low } \\
\text { doses are more effective than higher doses, with resulting importance of assessment of the } \\
\text { level of exposure }\end{array}$ \\
\hline $\begin{array}{l}\text { Several mechanisms of action } \\
\text { possibly coexisting }\end{array}$ & $\begin{array}{l}\text { Classical endocrine receptors as well as nonclassical endocrine or nonendocrine receptors } \\
\text { can be involved in addition to alterations in the rates of degradation of endogenous } \\
\text { hormones and EDCs }\end{array}$ \\
\hline
\end{tabular}

\section{Epigenetics and transgenerational endocrine disruption}

Epigenetics refers to changes in gene chemical characteristics (methylation, acetylation) that affect gene expression without alterations in gene composition. This mechanism appears to be critical for enduring and sexspecific responses to environmental experiences during early life depending on variations in maternal diet or sex 
steroids, for instance $\left[9^{\bullet \bullet}\right]$. Therefore, involvement of epigenetics in the mechanism of EDC effects could be anticipated. Of the utmost importance is the finding that transient exposure of fetal rodents to EDCs (vinclozolin, methoxychlor) at the time of germ cell line differentiation results in effects, including alterations of DNA methylation and fertility impairment, that are transferred to several subsequent generations [16]. Further, transgenerational effects were shown to involve energy balance and other aspects of reproduction, including behavior. In a study performed three generations after the progenitors were exposed to vinclozolin, female rodents preferred males with no history of exposure for mating [17]. These findings might suggest epigenetic changes in the neuroendocrine components of sexual behavior regulation. Direct evidence of epigenetic mechanisms in the hypothalamus in relation to sexual differentiation has been obtained recently [18], as well as effects on methylation pattern of the promoter of estrogen receptor beta gene in the adult ovary [19]. Recently, hypermethylation was found to explain why a homeobox gene controlling uterine organogenesis showed altered expression after fetal exposure to DES [20]. Overall, those findings emphasize again the critical role of prenatal and early postnatal life. The transgenerational effects and epigenetic mechanisms deserve further studies in different species and, if possible, epidemiological investigations in clinical conditions that could match some of the experimental observations.

\section{Clinical and experimental evidence suggestive of endocrine disruption of growth and development}

In order to confirm the reality of endocrine disruption, it can be helpful to assess the effects of given EDCs in a developmental perspective and through comparison of human and animal data. This is the purpose of Table 4 for four EDCs. Quite clearly, neonatal period and adulthood are the times when most effects of EDCs are reported, whereas few observations have been made so far during growth and development, that is in infancy, childhood and adolescence $\left[2^{\bullet}\right]$. It appears from Table 4 that humans and laboratory animals share common disturbances after exposure to DES, DDT and phthalates. In addition, these three EDCs account for anomalies of sex differentiation, though DES and DDT are primarily estrogen agonists, whereas phthalates are antiandrogenic. So far, human evidence of BPA effects is limited. Finally, the reproductive system is most obviously affected by EDCs, though evidence is emerging that aspects of energy balance are involved as well.

Table 4 Comparative effects of four endocrine-disrupting compounds on reproductive system and metabolism in humans and animals in relation to the periods of appearance

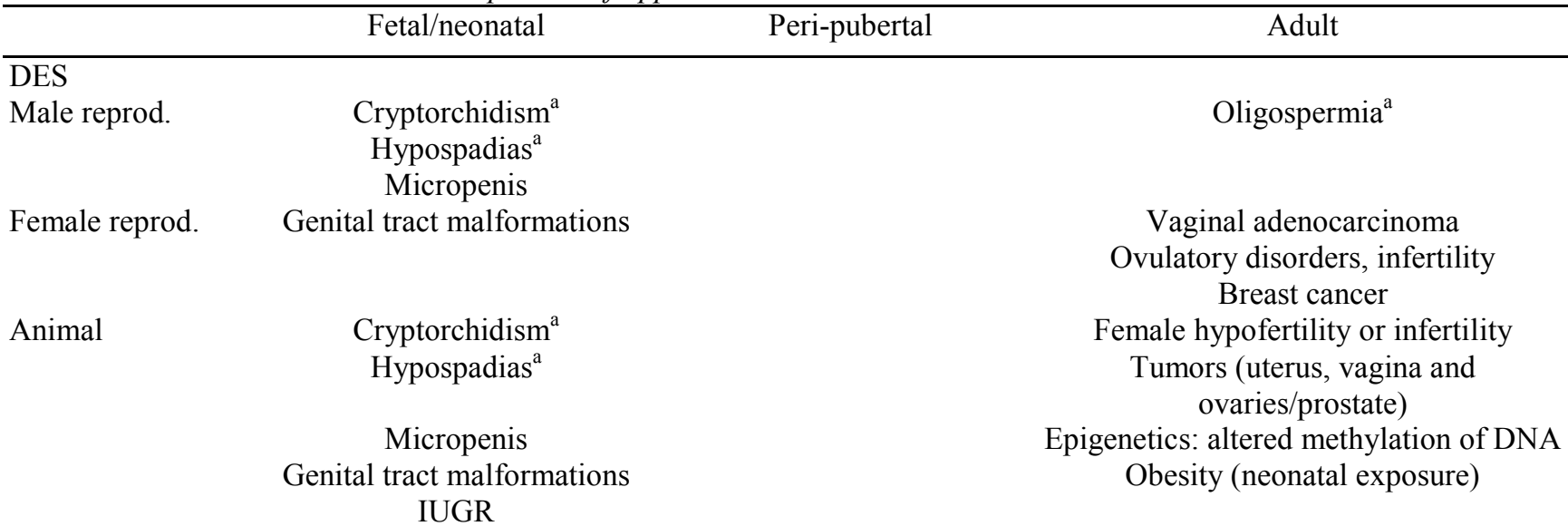

DDT

Male reprod.

Female reprod.

$$
\text { Cryptorchidism }
$$

Animal

Phthalates

Male reprod.

Female reprod.

Metabolic

Animal

Disorders of sexual differentiation (micropenis)

Female sexual precocity

Secondary central precocious puberty

Cryptorchidism $^{\mathrm{a}}$

Hypospadias $^{\mathrm{a}}$

Reduced anogenital distance

Cryptorchidism $^{\mathrm{a}}$

Premature thelarche
Ovulatory disorders Increased breast cancer risk

Reduced lactation

Male hypofertility

Ovulatory disorders

Oligospermia $^{\mathrm{a}}$

(Testicular cancer ${ }^{\mathrm{a}}$ )

Urinary concentr. correlated with BMI Oligospermia $^{\mathrm{a}}$ 
Reduced anogenital distance

Lowered insulin and leptin plasma concentration

BPA

Female reprod.

Metabolic

Animal

Increased adipogenesis

\section{PCOS}

Urinary concentrations correlated with cardiovascular disease incidence Premature ovarian failure Breast cancer

Predisposition to prostate cancer Insulin resistance

BPA, bisphenol A; DDT, dichlorodiphenyltrichloroethane; DES, diethylstilbestrol; IUGR, intrauterine growth retardation; PCOS, polycystic ovary syndrome; reprod., reproductive system. ${ }^{\mathrm{a}}$ The testicular dysgenesis syndrome.

Puberty warrants some discussion in relation to EDCs since it is a crucial event in growth and development together with achievement of reproductive capacity. Around the year 2000, two large American studies provided evidence of earlier onset of puberty [21,22]. Very recently relatively similar findings were obtained in Denmark and Belgium $\left[23^{\circ}, 24\right]$. In all four studies, it appeared that onset of breast development was more affected than menarcheal age. Because those changes in pubertal timing were concomitant with the epidemic of obesity in the USA, the pathophysiological involvement of fat mass, possibly through leptin [21,22,25], was hypothesized in that country. However, the recent changes in pubertal timing in Denmark were not associated with changes in

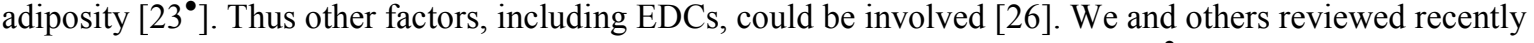
association between exposure to EDCs and variations in pubertal timing [27, 28, 29 ${ }^{\circ}$. In girls, DDE and DDT as well as PCBs and polybrominated biphenyls tended to be associated with early timing, whereas late timing could be observed after exposure to dioxins. Phytoestrogens did not show any effect. In boys, PCBs could also account for some pubertal delay. In a very recent American study of urinary biomarkers of EDCs in a cohort of 1151 girls aged 6-8 years, it was concluded that there was a weak positive association of urinary phthalates with timing of breast development [30]. This observation may have been limited by the studied EDCs and, more importantly, a time factor if pubertal timing is dependent on exposure to EDCs in fetal and early postnatal life.

Additional evidence of possible environmental effects on pubertal timing in humans came from studies in children migrating for international adoption. As cohorts, they appeared to mature earlier than children in the foster countries and in the countries of origin [31]. Also, sexual precocity requiring gonadotropin releasing hormone $(\mathrm{GnRH})$ agonist therapy was much more common in those migrating children than in others [32,33]. On the basis of increased serum levels of DDE, a derivative of the estrogenic insecticide DDT found among migrating children, we hypothesized that early exposure to this EDC and subsequent withdrawal due to migration could account for a neuroendocrine pathogenetic mechanism of secondary central precocious puberty $[31,32]$. This hypothesis was substantiated in a rat model [7,34]. The mechanistic interpretation is that, during exposure to DDT, estrogenic effects account for both peripheral and central (neuroendocrine) stimulation. However, due to concomitant negative feedback inhibition at the pituitary level, the central effects are not translated into gonadotropin stimulation of the ovaries until the pituitary inhibition disappears following migration into a DDT-free environment. In a study of internationally adopted girls aged 5-8 years and still clinically prepubertal, Teilmann and co-workers [35] reported that serum follicle stimulating hormone and estradiol levels were already elevated in several girls, confirming early pituitary-ovarian activity after migration. The above mechanism is comparable to that operating in other conditions with peripheral precocious puberty (e.g. congenital adrenal hyperplasia, adrenal or gonadal tumors) followed by secondary central precocious puberty after the peripheral disorder is cured by medical or surgical treatment [31]. However, the very long halflife of the DDT derivative DDE could have biased the study. Many other EDCs with shorter half-lives, and thus undetectable at the time of sexual precocity diagnosis, could have been involved as well. Moreover, it is likely that other factors, including recovery from earlier nutritional as well as psychosocial deprivation, could play some role in this particular condition [36].

\section{Endocrine disruption of growth and development: a common early homeostatic disturbance?}

The neuroendocrine system in the hypothalamus is a common place for regulation of different aspects of homeostasis, including reproduction and energy balance. It is also involved, during fetal and neonatal life, in programming mechanisms accounting for the 'developmental origin of health and diseases' [10]. Peripheral messengers from the gonads (e.g. sex steroids) and from adipose tissue (e.g. leptin, adiponectin) can also play 
important regulatory roles in linking energy balance and reproduction throughout life. In Fig. 1 are integrated some of the many connections between homeostasis of reproduction and homeostasis of energy balance, centrally and peripherally, during both prenatal/neonatal and postnatal life [29 ${ }^{\bullet}$.

Figure 1 Schematic representation of the interactions between homeostasis of reproduction and energy balance as well as hypothalamic effectors and peripheral effectors in the neuroendocrine mechanisms involved in effects on pubertal timing, reproductive function, adiposity and metabolism (modified from [29•])

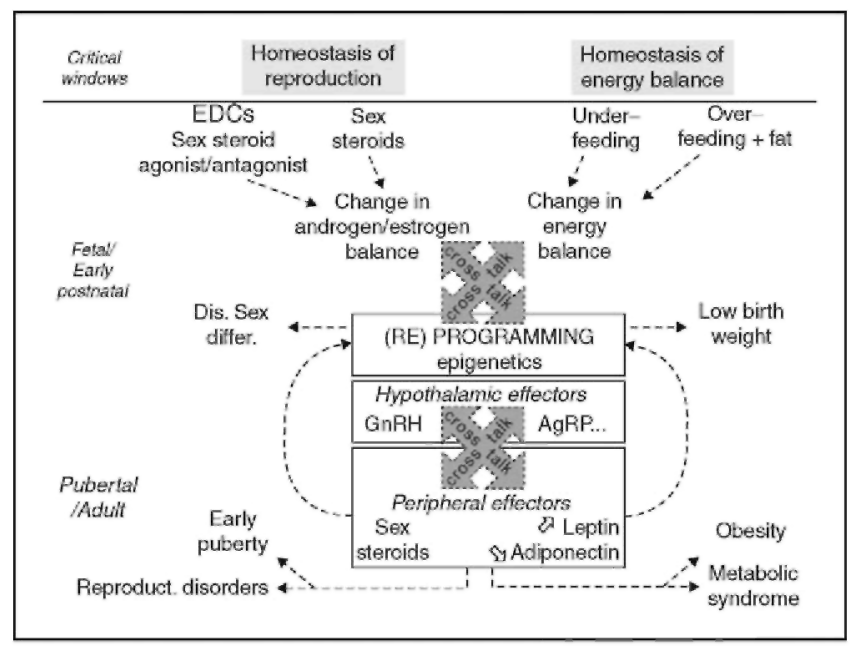

AgRP, Agouti-related protein; Dis. Sex differ., disorders of sex differentiation; EDCs, endocrine disrupting compounds.

Feto-maternal malnourishment or overfeeding with fat, as well as fetal exposure to sex steroids or endocrine disrupters such as DES and BPA, were shown to possibly result in low birth weight, early puberty, ovulatory disorders, obesity in adulthood and metabolic syndrome $\left[10,37^{\bullet}, 38,39^{\circ}\right]$. Both sex steroids and leptin are involved in early organizational effects in the hypothalamus that affect respectively the central control of reproduction $\left[40^{\circ}\right]$ and energy balance $\left[41^{\circ}\right]$. Peripherally, whereas EDC effects on male and female reproductive tract have been extensively described $\left[2^{\circ}\right]$, EDCs appeared more recently to cause induction of cell differentiation and adipogenesis [42] as well as lipid accumulation in differentiated adipocytes [43]. Gestational and lactational exposure to BPA resulted in increased adipogenesis at weaning in female rats [44]. Adiponectin, a factor protecting against obesity and insulin resistance, could play a role as well. Using mature abdominal adipocytes in vitro, BPA reduced the secretion of several adipokines including adiponectin $[45,46]$. It was suggested recently that obesity and metabolic syndrome could involve primary peripheral mechanisms through early impact of nutrition on increased adipogenic and lipogenic capacity of adipocytes $\left[47^{\circ}\right]$. The hypothesis was also raised that EDC effects on adipose tissue and energy balance could provide the basis of a toxicological mechanism in the obesity epidemic $\left[39^{\circ}, 48\right]$. Since soy-derived products are widely used in infancy, data obtained with phytoestrogens deserve special attention. Adiposity is reduced and insulin sensitivity increased in mice fed from conception to adulthood with a phytoestrogen-rich diet [49].

There are several lines of experimental and clinical evidence of cross-talk between the systems controlling reproduction on the one hand and energy balance on the other hand. Experimentally, reduced serum leptin levels are observed neonatally in association with reduced anogenital distance after fetal exposure to phthalates [50]. During postnatal life, leptin is an important link between energy balance and reproduction through facilitatory effects on GnRH secretion [31,51]. Through inhibition of adiponectin release, EDC could facilitate GnRH secretion, since immortalized GnRH neurons were shown to express adiponectin receptors and GnRH release was reduced in the presence of adiponectin [52]. Clinically, cross-talk is supported by the recent finding that fast weight gain in infancy between birth and 9 months predicts increased adiposity at 10 years and early menarcheal age [53]. Ibáñez et al. [13] reported that IUGR was associated with increased risk of premature pubarche, hyperinsulinism, ovarian hyperandrogenism and PCOS. These findings can be correlated with several experimental effects of manipulation of nutrition or exposure to sex steroids or EDCs in the fetus as detailed above. Of particular interest is the observation that IUGR is associated with increased visceral adiposity and reduced serum levels of adiponectin in childhood [54]. The latter effect parallels BPA-induced reduction of 
adiponectin production by adipocytes $[45,46]$. All together, those findings indicate that both the human reproductive system and energy balance system share a possible fetal/early postnatal determinism of adult disorders under the influence of early nutritional conditions and/or early exposure to EDCs, with mechanistic crosstalk between the two systems.

\section{Conclusion and recommendations for the pediatrician}

Due to ubiquity and multiplicity of EDCs, their environmental impact on health becomes an increasing matter of concern. Fetal and early postnatal periods are most critical for adverse health consequences, most of which, however, are expressed phenotypically only after several decades in humans. Additional concern arises from epigenetics, which possibly accounts for heritability of altered gene expression after exposure to EDCs. While research efforts are pursued to further delineate the consequences of exposure to EDCs in humans and wildlife, the precautionary principle should be followed. The ban on polycarbonate baby bottles by Canadian authorities in 2008 and the recent FDA statement about BPA exposure of very young children [55] are consistent with that principle. Recommendations for the pediatrician taking care of young children are proposed in Table 5 . They are relevant as well for gynecologists taking care of pregnant women, and they require continuing adjustment based on new findings from clinical and experimental research.

Table 5 Recommendations aiming at protection of pregnant women, newborns and infants from endocrine disrupting compounds

\begin{tabular}{|c|c|}
\hline Condition & Measure \\
\hline \multicolumn{2}{|l|}{ Diagnosis } \\
\hline Newborn with IUGR or DSD & $\begin{array}{l}\text { Investigate for presence of EDCs in child and mother plasma and breast milk; } \\
\text { store samples for future assays }\end{array}$ \\
\hline $\begin{array}{l}\text { Epidemics of DSD, pubertal or thyroid } \\
\text { anomalies }\end{array}$ & Investigate for presence of EDCs in child plasma and urine \\
\hline \multicolumn{2}{|l|}{ Nutrition and management } \\
\hline Baby bottles & $\begin{array}{l}\text { Prioritize glass; using plastics, exclude polycarbonate } \hat{\imath} \text { and prefer polyethylene } \\
\text { or polypropylene }\end{array}$ \\
\hline Food heating & Glass recipients; no plastic in microwaves \\
\hline Food/liquid containers & Prefer glass to plastics or metal cans \\
\hline Cosmetics & $\begin{array}{l}\text { Avoid unnecessary skin cream or lotion; when necessary, prioritize products } \\
\text { without parabens }\end{array}$ \\
\hline Inpatient hospital care & Avoid or limit perfusion material containing phthalates \\
\hline
\end{tabular}

\section{Acknowledgements}

The work was supported by grants from the European Commission (EDEN project, contract QLRT-200100269), the Fonds National de la Recherche Scientifique (FRS-FNRS 3.4.573.05F and 3.4.567.09F), the Faculty of Medicine at the University of Liège (Léon Frédéricq Foundation) and the Belgian Study Group for Paediatric Endocrinology.

\section{References and recommended reading}

Papers of particular interest, published within the annual period of review, have been highlighted as:

- of special interest

-• of outstanding interest

Additional references related to this topic can also be found in the Current World Literature section in this issue (pp. 554-555).

1 Herbst AL, Ulfelder H, Poskanzer DC. Adenocarcinoma of vagina. Association of maternal stilbestrol therapy with tumor appearance in young women. N Engl J Med 1971; 284:878-881.

$2^{\bullet}$ Diamanti-Kandarakis E, Bourguignon JP, Giudice LC, et al. Endocrine-disrupting chemicals: an Endocrine Society scientific 
Published in : Current Opinion in Pediatrics (2010), vol. 22, pp. 470-477.

Status : Postprint (Author's version)

statement. Endocr Rev 2009; 30:293-342.

This comprehensive review addresses the different aspects of endocrine disruption based on the systems and functions possibly altered by EDCs.

3 Third national report on human exposure to environmental chemicals. Atlanta: Center for Disease Control and Prevention; 2005.

4 Kortenkamp A. Lowdose mixture effects of endocrine disrupters: implications for risk assessment and epidemiology. Int J Androl 2008; $31: 233-240$.

5 Rivas A, Fisher J, McKinnell C, et al. Induction of reproductive tract developmental abnormalities in the male rat by lowering androgen production or action in combination with a low dose of diethylstilbestrol : evidence tor importance otthe androgen-estrogen balance. Endocrinology 2002; 143:4797-4808.

6 Colon I, Caro D, Bourdony CJ, Rosario O. Identification of phthalate esters in the serum of young Puerto Rican girls with premature breast development. Environ Health Perspect 2000; 108:895-900.

7 Rasier G, Parent AS, Gérard A, et al. Mechanisms of interaction of endocrine disrupting chemicals with glutamate-evoked secretion of gonadotropin-releasing hormone. Toxicol Sci 2008; 102:33-41.

$8 \quad$ Barker DJP. The developmental origins of adult disease. Eur J Epidemiol 2003; 18:733-736.

9•• McCarthy MM, Auger AP, Bale TL, et al. The epigenetics of sex differences in the brain. J Neurosci 2009; 29:12815-12823.

This state-of-the-art review aims at the epigenetic mechanisms of sex differences in brain and behavior and the heritability of epigenetic regulation of gene expression including the effects of sex steroids and EDCs.

10 Gluckman PD, Hanson MA. The developmental origins of the metabolic syndrome. Trends Endocrinol Metab 2004; 15:183-187.

11 Unsworth WP, Taylor JA, Robinson JE. Prenatal programming of reproductive neuroendocrine function: the effect of prenatal androgens on the development of estrogen positive feedback and ovarian cycles in the ewe. Biol Reprod 2005; 72:619-627.

12 Savabieasfahani M, Kannan K, Astapova O, et al. Developmental programming: differential effects of prenatal exposure to bisphenol-a or methoxychlor on reproductive function. Endocrinology 2006; 147:5956-5966.

13 Ibáñez L, Francois I, Potau N, de Zegher F. Precocious pubarche, hyper-insulinism and ovarian hyperandrogenism in girls: relation to reduced fetal growth. J Clin Endocrinol Metab 1998; 83:3558-3662.

14 Skakkebaek NE, Rajpert-De Meyts E, Main KM. Testicular dysgenesis syndrome: an increasingly common developmental disorder with environmental aspects. Hum Reprod 2001; 16:972-978.

15 Fisher JS, Macpherson S, Marchetti N, Sharpe RM. Human testicular dysgenesis syndrome: a possible model using in-utero exposure of the rat to dibutyl phthalate. Hum Reprod 2003; 18:1383-1394.

16 Anway MD, Cupp AS, Uzumcu M, Skinner MK. Epigenetic transgenerational actions of endocrine disruptors and male fertility. Science 2005; 308:1466-1469.

17 Crews D, Gore AC, Hsu TS, et al. Transgenerational epigenetic imprints on mate preference. Proc Nat Acad Sci (USA) 2007; 104:5942-5946.

18 Murray EK, Hien A, de Vries GJ, Forger NG. Epigenetic control of sexual differentiation of the bed nucleus of the stria terminalis. Endocrinology 2009; 150:4241-4247.

19 Mahakali Zama A, Uzumcu M. Fetal and neonatal exposure to the endocrine disruptor methoxychlor causes epigenetic alterations in adult ovarian genes. Endocrinology 2009; 150:4681-4691.

20 Bromer JG, Wu J, Zhou Y, Taylor HS. Hypermethylation of Homeobox A10 by in utero diethylstilbestrol exposure: an epigenetic mechanism for altered developmental programming. Endocrinology 2009; 150:3376-3382.

21 Herman-Giddens ME, Slora EJ, Wasserman RC, et al. Secondary sexual characteristics and menses in young girls seen in office practice: a study from the Pediatric Research in Office Settings network. Pediatrics 1 997; 99:505-512.

22 Lee PA, Guo SS, Kulin HE. Age of puberty: data from the United States of America. APMIS 2001; 109:81-88.

23 Aksglaede L, Serensen K, Petersen JH, et al. Recent decline in age at breast development: the Copenhagen puberty study. Pediatrics 2009; 123:e932-e939.

In a thorough epidemiological study of growth and pubertal development in two Danish cohorts at 15 -year interval, resumption of a secular 
Published in : Current Opinion in Pediatrics (2010), vol. 22, pp. 470-477.

Status : Postprint (Author's version)

trend in earlier breast development independent of BMI changes is convincingly shown.

24 Roelants M, Hauspie R, Hoppenbrouwers K. References for growth and pubertal development from birth to 21 years in Flanders, Belgium. Ann Hum Biol 2009; 36:680-694.

25 Himes JH. Examining the evidence for recent secular changes in the timing of puberty in US children in light of increases in the prevalence of obesity. Mol Cell Endocrinol 2006; 254-255:13-21.

26 Teilmann G, Juul A, Skakkebaek NE, Toppari J. Putative effects of endocrine disrupters on pubertal development in the human. Best Pract Res Clin Endocrinol Metab 2002; 16:105-121.

27 Schoeters G, Den Hond E, Dhooge W, et al. Endocrine disruptors and abnormalities of pubertal development. Basic Clin Pharmacol Toxicol 2008; 102:168-175.

28 Jacobson-Dickman E, Lee MM. The influence of endocrine disruptors on pubertal timing. Curr Opin Endocrinol Diab Obesity 2009; 16: $25-30$

29 Bourguignon JP, Rasier G, Lebrethon MC, et al. Neuroendocrine disruption of pubertal timing and interactions between homeostasis of reproduction and energy balance. Mol Cell Endocrinol (in press).

The merit of this review study is the emphasis on the mechanistic similarities and links between early determinism of changes in the control of reproduction and energy balance in the perspective of endocrine disruption.

30 Wolff MS, Teitelbaum SL, Pinney SM, et al. and the Breast Cancer and Environment Research Centers. Investigation of relationships between urinary biomarkers of phytoestrogens, phthalates, and phenols and pubertal stages in girls. Env Health Perspect. [Epub ahead of print]

31 Parent AS, Teilmann G, Juul A, et al. The timing of normal puberty and the age limits of sexual precocity: variations around the world, secular trends, and changes after migration. Endocr Rev 2003; 24:668-693.

32 Krstevska-Konstantinova M, Charlier C, Craen M, et al. Sexual precocity after immigration from developing countries to Belgium: evidence of previous exposure to organochlorine pesticides. Hum Reprod 2001; 16:1020-1026.

33 Teilmann G, Pedersen CB, Skakkebaek NE, Jensen TK. Increased risk of precocious puberty in internationally adopted children in Denmark. Pediatrics 2006; 118:e391-e399.

34 Rasier G, Parent AS, Gérard A, et al. Early maturation of gonadotropin-releasing hormone secretion and sexual precocity after exposure of infantile female rats to estradiol or dichlorodiphenyltrichloroethane. Biol Reprod 2007; 77:734-742.

35 Teilmann G, Boas M, Petersen JH, et al. Early pituitary-gonadal activation in 5-8 years old adopted girls before clinical signs of puberty: a study of 99 foreign adopted girls and 93 controls. J Clin Endocrinol Metab 2007; 92:2538-2544.

36 Dominé F, Parent AS, Rasier G, et al. Assessment and mechanism of variations in pubertal timing in internationally adopted children: a developmental hypothesis. Eur J Endocrinol 2006; 155:S17-S25.

37 Newbold RR, Padilla-Banks E, Jefferson WN. Environmental estrogens and obesity. Mol Cell Endocrinol 2009; 304:84-89.

The literature from experimental animal studies documenting an association of environmental estrogens and the development of obesity is reviewed and the particular case of some EDCs like DES and BPA is further described.

38 Sloboda DM, Howie GJ, Pleasants A, et al. Pre and postnatal nutritional histories influence reproductive maturation and ovarian function in the rat. PLoS ONE 2009; 4:e6744.

39 Heindel JJ, vom Saal FS. Role of nutrition and environmental endocrine disrupting chemicals during the perinatal period on the aetiology of obesity. Mol Cell Endocrinol 2009; 304:90-96.

Weight gain throughout entire life is shown to be influenced by environmental factors determining growth during fetal and neonatal life, including nutrition and EDCs throughout life.

40 Balthazart J, Cornil CA, Charlier TD, et al. Estradiol, a key endocrine signal in the sexual differentiation and activation of reproductive behavior in quail. J Exp Zool A Ecol Genet Physiol 2009; 311:323-345.

Using the Japanese quail as paradigm, the organizational, activational and nongenomic effects of estradiol on sexual differentiation and reproductive behavior are reviewed. This represents a solid basis for pathophysiological understanding of EDC interaction with estrogen action and metabolism in the CNS.

41 ${ }^{\bullet}$ Bouret SG. Role of early hormonal and nutritional experiences in shaping feeding behavior and hypothalamic development. J Nutr $2010 ; 140: 653-657$ 
Published in : Current Opinion in Pediatrics (2010), vol. 22, pp. 470-477.

Status : Postprint (Author's version)

Leptin's role in developmental and structural organization of the hypothalamic control of energy balance substantiates a mechanism for the developmental origin of obesity and metabolic disorders.

42 Grün F, Watanabe H, Zamanian Z, et al. Endocrine-disrupting organotin compounds are potent inducers of adipogenesis in vertebrates. Mol Endocrinol 2006; 20:2141-2155.

43 Wada K, Sakamoto H, Nishikawa K, et al. Life style-related diseases of the digestive system: endocrine disruptors stimulate lipid accumulation in target cells related to metabolic syndrome. J Pharmacol Sci 2007; 105:133-137.

44 Somm E, Schwitzgebel VM, Toulotte A, et al. Perinatal exposure to bisphenol a alters early adipogenesis in the rat. Environ Health Perspect 2009; 117:1549-1555.

45 Hugo ER, Brandebourg TD, Woo JG, et al. Bisphenol A at environmentally relevant doses inhibits adiponectin release from human adipose tissue explants and adipocytes. Environ Health Perspect 2008; 116:1642-1647.

46 Ben-Jonathan N, Hugo ER, Brandebourg TD. Effects of bisphenol A on adipokine release from human adipose tissue: implications for the metabolic syndrome. Mol Cell Endocrinol 2009; 304:49-54.

47 ${ }^{\bullet}$ Muhlhausler B, Smith SR. Early-life origins of metabolic dysfunction: role of the adipocyte. Trends Endocrinol Metab 2009; $20: 51$-57.

Early regulation at the adipocyte level with emphasis on differences between visceral and subcutaneous fat is reviewed as a fetal determinant of adult obesity and metabolic dysfunction.

48 Baillie-Hamilton PF. Chemical toxins: a hypothesis to explain the global obesity epidemic. J Altern Complement Med 2002; 8:185-192.

49 Cederroth CR, Vinciguerra M, Gjinovci A, et al. Dietary phytoestrogens activate AMP-activated protein kinase with improvement in lipid and glucose metabolism. Diabetes 2008; 57:1176-1185.

50 Boberg J, Metzdorff S, Wortziger R, et al. Impact of diisobutyl phthalate and other PPAR agonists on steroidogenesis and plasma insulin and leptin levels in fetal rats. Toxicology 2008; 250:75-81.

51 Lebrethon MC, Aganina A, Fournier M, et al. Effects of in vivo and in vitro administration of ghrelin, leptin and neuropeptide mediators on pulsatile gonadotrophin-releasing hormone secretion from male rat hypothalamus before and after puberty. $\mathrm{J}$ Neuroendocrinol 2007; 19:181-188.

52 Wen JP, Lv WS, Yang J, et al. Globular adiponectin inhibits GnRH secretion from GT1-7 hypothalamic GnRH neurons by induction of hyperpolarization of membrane potential. Biochem Biophys Res Commun 2008; 371:756-761.

53 Ong KK, Emmett P, Northstone K, et al. Infancy weight gain predicts childhood body fat and age at menarche in girls. J Clin Endocrinol Metab 2009; 94:1527-1532.

54 Ibáñez L, Lopez-Bermejo A, Díaz M, et al. Low-birth weight children develop lower sex hormone binding globulin and higher dehydroepiandrosterone sulfate levels and aggravate their visceral adiposity and hypoadiponectinemia between six and eight years of age. $\mathrm{J}$ Clin Endocrinol Metab 2009; 94:3696-3699.

55 US Food and Drug Administration. Update on bisphenol A for use in food contact applications. www.fda.gov (Accessed 15 January 2010). 